\title{
Molecular characterization of Leishmania tropica and Leishmania major from stray dogs and patients in Saudi Arabia
}

Abdullah D Alanazi ( $\square$ aalanazi@su.edu.sa )

Shaqra University https://orcid.org/0000-0002-4862-7668

Abdulazi S Alouffi S Alouffi

King Abdulaziz City for Science And Technology

Mohamed S Alyousif S Alyousif

King Saud University

Abdulsadah A Rahi

University of Wasit

Magada A Ali

University of Wasit

Fabio A Brayner

Universidade Federal do Pernambucu, Recife

Jairo Alfonso Mendoza-Roldan

Universita degli Studi di Bari

Domenico Otranto

Universita degli Studi di Bari

\section{Research}

Keywords: L. tropica, L. major, Dogs, Patients, kDNA, n PCR, Saudi Arabia

Posted Date: February 10th, 2020

DOI: https://doi.org/10.21203/rs.2.22961/v1

License: (1) (1) This work is licensed under a Creative Commons Attribution 4.0 International License. Read Full License 


\section{Abstract}

Background: Leishmania major and Leishmania tropica cause cutaneous leishmaniasis in humans and dogs in several parts of the world, with a large number of cases recorded in the Middle East. However, when occurring in sympatry in the same area, the role of each species in the epidemiology of cutaneous leishmaniasis is not clear.

Methods: To determine the prevalence and to identify the species of Leishmania that infect humans and stray dogs in Riyadh and Al-Qaseem (Saudi Arabia), blood samples were collected from stray dogs $(\mathrm{n}=$ $311)$ and human patients $(n=27)$. A conventional PCR coupled with a nested PCR (n PCR) were applied in this study.

Results: A conventional PCR coupled with a nested PCR (n PCR) showed that seven patients $(25.9 \%)$ from Riyadh city and Al-Qaseem province were infected by $L$. major and $L$. tropica and five dogs $(1.6 \%)$ by $L$. tropica.

Conclusions: This is one of the first molecular studies of leishmaniasis from Saudi Arabia. The relationship between the sand fly vectors and the reservoirs of both Leishmania spp. is still scarcely known in this region, and further epidemiological investigations of domestic and wild canine infected with $L$. major and $L$. tropica are needed towards a control and prevention of the infection in canine and human populations.

\section{Introductions}

Leishmaniases are a complex of sand fly transmitted protozoa diseases, listed amongst the neglected tropical diseases affecting millions of people, mainly the world's most vulnerable populations [1]. These diseases are worldwide associated to the occurrence of phlebotomine sand flies of the genus Phlebotomus in the Old World and Lutzomyia in the New World. Leishmaniases include cutaneous (CL), visceral (VL) and mucocutaneous (ML) forms all of which have been reported in Saudi Arabia [2-4]. Moreover, in that Country CL by Leishmania major has the highest prevalence mainly in Riyadh, Qassim, Al-Madinah, Al-Hassa, Hail and Asir [5-7] with an estimated number of more than 26,300 cases [2] over the past 10 years (2006-2016). In addition, in Saudi Arabia there are several reports of leishmaniasis by Leishmania infantum, Leishmania arabica, Leishmania major and Leishmania tropica among dogs and humans [8-12]. In spite of the number of molecular studies available to diagnose and identify Leishmania species worldwide [13-16] there is a lack of information on CL in human and dog populations from endemic areas of Saudi Arabia $[17,18]$. Therefore, the aims of the current study were to detect and identify the Leishmania species infecting humans and stray dogs in Al-Qaseem province and Riyadh city, Saudi Arabia in order to better understand the epidemiology of the infection.

\section{Materials And Methods}

\subsection{Ethical approval}


This study was reviewed and approved by the Ethics Committee of the Department of Biological Science at Shaqra University, according to the ethical principles of animal research (protocol SH 2-2017).

\subsection{Study areas}

The investigation was conducted from January 2018 to May 2019 in Al-Qaseem province and Riyadh city, Saudi Arabia. Al-Qaseem province is located at the central part of Saudi Arabia (latitude $25^{\circ}-23^{\circ} \mathrm{N}$ and longitude $42^{\circ}-24^{\circ} \mathrm{E}$ ). It has an area of about $58.046 \mathrm{~km}^{2}$ and was reported to be inhabited by approximately 1,423.000 people in 2017 (General Authority for Statistic, 2017). Riyadh city is the capital of Saudi Arabia (latitude $24^{\circ}-08^{\circ} \mathrm{N}$ and longitude $47^{\circ}-18^{\circ} \mathrm{E}$ ), with an area of about $1798 \mathrm{~km}^{2}$ and inhabited by approximately seven million people in 2016 [19] (Figure 1).

\subsection{Patients Biopsy tissue collections and gDNA extraction}

A total of 27 suspected patients were attended in King Saud Medical City in Riyadh city $(n=16)$ and Buraidah Central Hospital $(n=11)$ in Al-Qaseem province. All samples were diagnosed after clinical and microscopy examination [20]. Briefly, skin biopsies (i.e., 5-10 mm of diameter) were taken under sterile conditions from the border of the ulcer and cutaneous lesions and DNA samples were extracted from all biopsies by MagNaA pure DNA extraction Pure LC DNA Isolation Kit (Roche Applied Science, Mannheim, Germany) according to the manufacturer's instruction (Roche) and the extracted gDNA was checked by Nanodrop spectrophotometer (Thermo, USA), and an aliquot (100 $\mu$ l of gDNA from each sample) stored at $-20^{\circ} \mathrm{C}$ prior to $\mathrm{nPCR}$ amplification and analysis.

\subsection{Sampling of stray dogs}

From January 2018 to May 2019, 311 stray dogs were trapped in Al-Qaseem province by bait traps $\left(\right.$ Havahart $\left.^{\circledR}\right)$, dogs examined physically for $C L$ in the field and a blood sample of 2-5 ml from the cephalic vein into EDTA vacuum tubes (BD Vacutainer ${ }^{\circledR}$ Tube, Gribbles Pathology, VIC, Australia) and transported to the molecular laboratory, Shaqra University for DNA extraction and further molecular analysis. Seven of the above animals were suspected for $\mathrm{CL}$ due to the presence of cutaneous nodules or ulcerated lesions on the skin. Skin biopsies ( $5 \mathrm{~mm}$ in diameter) were taken under sterile conditions from the border of the ulcer and inoculated into medium M199 supplemented (Gibco, Life technologies, Germany) with 25 $\mathrm{mmol} / \mathrm{L}$ HEPES (pH:7.5) and 20\% fetal bovine serum (Gibco, Life technologies, Germany) followed by incubation at $24{ }^{\circ} \mathrm{C}$. Ten days later parasites were harvested and washed with ice-cold phosphate buffered saline (PBS, pH: 7.4) and stored in $-20^{\circ} \mathrm{C}$ before DNA isolation.

\subsection{Leishmania Nested PCR (nPCR)}

The specific external CSB2XF primers (5区-ATTTTTCGCGATTTTCGCAGAAACG-3区) and CSB1XR (5区CGAGTAGCAGAAACTCCCGTTCA-3囚) were used initially. In the second step, specific internal $13 Z$ primers (5囚-ACTGGGGGTTGGTGTAAAATAG-3囚) and LiR (5囚-TCGCAGAACGCCCCT-3囚) were applied [21]. These primers were able to track the variable part of all forms of the Leishmania kDNA minicircle [21]. The first 
step of PCR master mix that included CSB2XF and CSB1XR were applied using AccuPower ${ }^{\circledR}$ PCR PreMix kit (Bioneer, Daejeon, Korea). The prepared PCR premix volumes contained $\mathrm{KCl} 30 \mathrm{mM}, \mathrm{MgCl}_{2} 1.5 \mathrm{mM}$, Tris-HCL (pH 9.0) 10mM, Taq DNA polymerase, and dNTP were adjusted to $2 \mu$ l. In addition, $1 \mu$ l of the first step of each initial CSB1XR and CSB2XF primers at concentrations of 10 pmol (Bioneer, Daejeon, Korea) and $3 \mu \mathrm{l}$ of genomic DNA were added to the complex. Finally, $13 \mu \mathrm{l}$ of deionized water $(\mathrm{ddH} 2 \mathrm{O})$ were added for a total volume of $20 \mu \mathrm{l}$ for reaction. The reaction was performed in a thermal cycler (Techne TC-3000, USA) by set up the following conditions; initial denaturation temperature of $94^{\circ} \mathrm{C}$ for 5 min; followed by 30 cycles at denaturation $94^{\circ} \mathrm{C}$ for $30 \mathrm{~s}$, annealing $55^{\circ} \mathrm{C}$ for $60 \mathrm{~s}$, extension $72{ }^{\circ} \mathrm{C}$ for 60 $\mathrm{s}$, final extension at $72{ }^{\circ} \mathrm{C}$ for $7 \mathrm{~min}$ and then the reaction was held at $4{ }^{\circ} \mathrm{C}$. The second step of PCR included $13 Z$ and LiR primers and the same PCR master mix except $3 \mu \mathrm{L}$ of template PCR product. After that, PCR products were electrophoresed on a $1.5 \%$ agarose gel containing $1 \mu \mathrm{L} / \mathrm{mL}$ Syber safe (Thermo Scientific ${ }^{T M}$, Nalgene, UK) in Tris-acetate-EDTA buffer at $100 \mathrm{~V}$ for $45 \mathrm{~min}$ and visualized under UV imaging system (ImageQuant Laz4000, GE Healthcare Life Science, Hammersmith, UK). The size of each sample was estimated by comparison with a 100 bp DNA Ladder Marker (Solis BioDyne OU, Estonia).

\subsection{Lesishmania kDNA sequencing and phylogenetic analysis}

Positive amplified products of Leishmania species were sent to Macrogen (South Korea) for sequencing, and the results were compared with the sequences available in GenBank database using BLAST (http://blast.ncbi.nlm. nih.gov/). The phylogenetic analysis was performed based on NCBI-Blast alignment identification and maximum composite Likelihood method by phylogenetic tree UPGMA method (MEGA 7.0 version). Bootstrap values were determined with 1,000 replicates of the data sets [22]. The sequences will be deposited onto GenBank (AN will be provided in the R1).

\section{Results}

Of the 27 human patients examined five from Riyadh and two from Al-Qaseem were positive to L. major and $L$. tropica respectively (Figure 2 and 3 ). Of 311 dogs, seven (2.3\%) presented with thick cutaneous lesions (i.e., $1.5 \times 5$ centimeters) in different anatomical sites (e.g., nose, muzzle, abdomen and between fingers) and five of them were positive to $L$. tropica. Sequencing analysis of Leishmania kDNA confirmed that the five positive samples (nos. $\mathrm{H} 1-\mathrm{H} 5$ ) of the human patients from Riyadh were all L. major with a size ranging from about $441 \mathrm{bp}$ to $451 \mathrm{bp}$ yielding a nucleotide identity ranging from $99.34 \%$ to $99.56 \%$ with previous L. major sequences from Iran (AN LC036307.1). Leishmania sequences from two human patients (nos. $\mathrm{H} 1$ and $\mathrm{H} 3$ ) from Al-Qaseem were identical to L. tropica from Iran (AN AB678350.1) (Figure 4 and Table 1). Sequences of Leishmania kDNA from stray dogs (no. D2, D4 and D7) were closely related (i.e., $99.33 \%$ to $99.5 \%$ ) to kDNA of L. tropica from Iraq (MF166799.1), whereas two sequences (no. D5 and D6) displayed a close nucleotide identity (i.e., 99.55\%) to L. tropica kDNA from Iraq (AN MF166800.1;

Figure 4 and Table 1). Phylogenetic tree clustered L. major (no. H1-H5) and L. tropica (no H1 and H3) sequences from human samples to those from Iran (accession number LC036307.1 and AB678350.1, respectively), and the phylogenetic tree clustered L. tropica (no. D2, D4 and D7) and (no. D5 and D6) 
sequences from dog's samples to those from Iraq (accession number MF166799.1 and MF166800.1, respectively; Figure 4).

\section{Discussion}

This study provides molecular evidence of the circulation of L. major and L. tropica in human and dog populations from the investigated areas. The above Leishmania spp. have already been recorded as agents of cutaneous leishmaniases in Saudi Arabia and Middle Eastern countries [23-26]. However, $L$. tropica infection has been herein molecularly diagnosed for the first time in humans and dogs in the central part of the Saudi Arabia since it was previously reported in the west and southern west of Saudi Arabia in association with the distribution of the sand fly species (i.e., Phlebotomus sergenti), which is a proper vector for that species [27]. Conversely, L. major is more prevalent throughout the Country and can be found in the open deserts regions of Saudi Arabia [2, 28]. Previous studies in Saudi Arabia have reported the natural infection of $L$. major in dogs using enzymatic biochemical methods [29, 30], though no clinical information was available, nor serology or molecular confirmation were performed. The high nucleotide identity of human $L$. major and $L$. tropica isolates with those of Iran (accession number AB678350.1 and LC036307.1) as well as of dog L. tropica isolates with Iraq (accession number MF166799.1 and MF166800.1) was also confirmed by the phylogenetic dendrogram herein presented. This might be due to the distribution of similar sand flies species in the Middle East, which may act as proper vectors of both Leishmania spp. [24, 31].

Of the 25 species of Phlebotomus reported in Saudi Arabia only five (i.e., Phlebotomus papatasi, $P$. sergenti, Phlebotomus bergeroti, Phlebotomus kazeruni, and Phlebotomus arabicus) have been incriminated as vectors of $\mathrm{CL}[27,28,32,33]$. Of these, $P$. papatasi is the major and most predominant vector species for $L$. major [28, 32], while $P$. sergenti is the natural vector species for $L$. tropica [27]. Presence of $P$. papatasi and $P$. sergenti in Al-Qaseem province suggests that they could have a potential role in the transmission of human and canine leishmaniasis. Nonetheless, still more studies are required to elucidate the role of Phlebotomus spp. in CL disease transmission in Saudi Arabia.

Stray dogs have been often diagnosed in Saudi Arabia, with clinical disease associated with Leishmania species, however previous studies focused on the epidemiology, clinical, histopathological and biochemical aspects $[11,29,30]$. Conversely, molecular studies have reported the occurrence of dog infection by Leishmania spp. in Qatar [34], L. tropica in Iran [26, 35] and Israel [36, 37] and by L. major in Iraq [23] and Israel [25], which are in agreement with the current study. Though CL is endemic in many parts of Saudi Arabia, the paucity of data concerning the relationship between the disease, the vectors and reservoirs is a major hindrance to understand the transmission cycles in endemic areas. Data herein provided contribute to fill existing gaps in order to increase the alert by the Ministry of Health in Saud Arabia in preventing outbreaks and the spread of CL.

\section{Conclusion}


This is one of the first molecular epidemiological studies that detected and identified CL in stray dogs and patients from Saudi Arabia thus confirming that L. major and L. tropica are endemic in Al-Qaseem province and Riyadh City. However, it is still unclear the relationship between the sand fly vectors and reservoirs and their specific role in the transmission cycles in endemic areas of Saudi Arabia. More epidemiological and molecular studies

\section{Declarations}

\section{Ethics approval and consent to participate}

Blood and tissue sampling for this study was approved by the Ethical Research Committee, Shaqra University and complied with relevant guidelines for animal handling and welfare. (Approval no. SH 022017)

\section{Disclosure}

The authors declare that they have no competing interests.

\section{Funding}

Not applicable.

\section{Consent for publication}

Not applicable.

\section{Acknowledgements}

This project was kindly supported by Shaqra University and King Abdulaziz city for Science and Technology (KACST), Saudi Arabia. The authors would like to thank the Staff Members of the Biological Sciences Department, Faculty of Science and Humanities, Shaqra University for kind technical support.

\section{Authors' contributions}

ADA , ASA and AAR conceived the study. MSA, ASA performed field works. ASA collected patient's and dog's samples. ASA, AAR and MAA carried out the biopsy tissue collections and DNA extraction. MAA, AAR and FAR performed laboratory works and analyzed data. ADA, MSA and FAR wrote the first draft of the manuscript. JM-R, DO, RD and ADA reviewed and wrote the final draft of the manuscript. All authors read and approved the final manuscript.

\section{References}

1. WHO: Report on the Interregional meeting on leishmaniasis among neighbouring endemic countries in the Eastern Mediterranean, African and Europ, Amman,23-25 September 2018. 
2. Abuzaid AA, Abdoon AM, Aldahan MA, Alzahrani AG, Alhakeem RF, Asiri AM, Alzahrani MH, Memish ZA: Cutaneous Leishmaniasis in Saudi Arabia: A Comprehensive Overview. Vector-Borne and Zoonotic Diseases 2017, 17(10):673-684.

3. Sirdar MK, Al-Zahrani MH, Dahlan AA, Sahli AA, Mohamed WS, Hejri YM, Dafalla OM, Alattass MS, Hayder A, Noureldin EM: Epidemiology and incidence of leishmaniasis in Jazan region, Saudi Arabia (2007-2015): An overview. Journal of Entomology and Zoology Studies 2018; 6(5): 859-864.

4. Hawash YA, Ismail KA, Abdel-Wahab MM, Khalifa M: Diagnosis, treatment and clinical features of cutaneous Leishmaniasis in Saudi Arabia. The Korean Journal of Parasitology 2018, 56(3):229.

5. Al-Tawfiq JA, AbuKhamsin A: Cutaneous leishmaniasis: a 46-year study of the epidemiology and clinical features in Saudi Arabia (1956-2002). International Journal of Infectious Diseases 2004, 8(4):244-250.

6. Amin TT, Al-Mohammed HI, Kaliyadan F, Mohammed BS: Cutaneous leishmaniasis in Al Hassa, Saudi Arabia: epidemiological trends from 2000 to 2010. Asian Pacific Journal of Tropical Medicine 2013, 6(8):667-672.

7. Alanazi A, Alyousif M, Saifi M, Alanazi I: Epidemiological studies on cutaneous leishmaniasis in AdDawadimi District, Saudi Arabia. Tropical Journal of Pharmaceutical Research 2016, 15(12):27092712.

8. Alanazi A, Puschendorf R, AlyousiF M, Al-Khalifa M, Alharbl S, AL-Shehrl Z, Alanazl I, AL-Mohammed HI, YIraey Y: Molecular Detection of Leishmania spp. in Skin and Blood of Stray Dogs from Endemic Areas of Cutaneous Leishmaniasis in Saudi Arabia. Iranian Journal of Parasitology 2019, 14(2):231239.

9. Alanazi A, Rahi A, Ali M, Alyousif M, Alanazi I, Mahmoud M, Abdel-Shafy S, Alraey Y, Alouffi A: Molecular detection and phylogenetic analysis of Leishmania major in stray dogs in Riyadh Province, Saudi Arabia. Tropical Biomedicine 2019, 36(2):315-323.

10. Peters W, Elbihari S, Evans D: Leishmania infecting man and wild animals in Saudi Arabia. 2. Leishmania arabica n. sp. Transactions of the Royal Society of Tropical Medicine and Hygiene 1986, 80(4):497-502.

11. Elbihari S, Cheema A, El-Hassan A: Leishmania infecting man and wild animals in Saudi Arabia. 4. Canine cutaneous leishmaniasis in the Eastern Province. Transactions of the Royal Society of Tropical Medicine and Hygiene 1987, 81(6):925-927.

12. Al-Zahrani M, Peters W, Evans D: Visceral leishmaniasis in man and dogs in south-west Saudi Arabia. Transactions of the Royal Society of Tropical Medicine and Hygiene 1988, 82(6):857.

13. Akhavan AA, Mirhendi H, Khamesipour A, Alimohammadian MH, Rassi Y, Bates P, Kamhawi S, Valenzuela JG, Arandian MH, Abdoli H: Leishmania species: detection and identification by nested PCR assay from skin samples of rodent reservoirs. Experimental Parasitology 2010, 126(4):552-556.

14. Toz SO, Culha G, Zeyrek FY, Ertabaklar H, Alkan MZ, Vardarlı AT, Gunduz C, Ozbel Y: A real-time ITS1PCR based method in the diagnosis and species identification of Leishmania parasite from human and dog clinical samples in Turkey. PLoS Neglected Tropical Diseases 2013, 7(5):e2205. 
15. Silva RC, Richini-Pereira VB, Kikuti M, Marson PM, Langoni H: Detection of Leishmania (L.) infantum in stray dogs by molecular techniques with sensitive species-specific primers. Veterinary Quarterly 2017, 37(1):23-30.

16. Ferreira SA, Ituassu LT, Melo MN, Andrade AS: Evaluation of the conjunctival swab for canine visceral leishmaniasis diagnosis by PCR-hybridization in Minas Gerais State. Brazil Veteterinary Parasitology 2008, 152.

17. Rasheed Z, Ahmed AA, Salem T, Al-Dhubaibi MS, Al Robaee AA, Alzolibani AA: Prevalence of Leishmania species among patients with cutaneous leishmaniasis in Qassim province of Saudi Arabia. BMC public health 2019, 19(1):384.

18. El-Beshbishy HA, Al-Ali KH, El-Badry AA: Molecular characterization of cutaneous leishmaniasis in AlMadinah Al-Munawarah province, western Saudi Arabia. International Journal of Infectious Diseases 2013, 17(5):e334-e338.

19. General Authority for Statistic: Population Characteristics surveys, Saudi Arabia, pp. 25. https://www.stats.gov.sa/sites/default/files/population_characteristics_surveysar.pdf. 2017.

20. Akilov OE, Khachemoune A, Hasan T: Clinical manifestations and classification of Old World cutaneous leishmaniasis. International Journal of Dermatology 2007, 46(2):132-142.

21. Noyes HA, Reyburn H, Bailey JW, Smith D: A nested-PCR-based schizodeme method for identifying Leishmania kinetoplast minicircle classes directly from clinical samples and its application to the study of the epidemiology of Leishmania tropica in Pakistan. Journal of Clinical Microbiology 1998, 36(10):2877-2881.

22. Kumar S, Stecher G, Tamura K: MEGA7: Molecular Evolutionary Genetics Analysis version 7.0 for bigger datasets. Molecular Biology and Evolution 2016, 33(7):1870-1874.

23. Al-Bajalan MM, Niranji SS, Al-Jaf SM, Kato H: First identification of L. major in a dog in an endemic area of human cutaneous leishmaniasis in Iraq: molecular and phylogenetic studies. Parasitology Research 2018:1-6.

24. Al-Salem WS, Pigott DM, Subramaniam K, Haines LR, Kelly-Hope L, Molyneux DH, Hay SI, AcostaSerrano A: Cutaneous Leishmaniasis and Conflict in Syria. Emerg Infect Dis 2016, 22(5):931-933.

25. Baneth G, Nachum-Biala Y, Simon MS, Brenner O, Gaier S, Rojas A, Yasur-Landau D: Leishmania major infection in a dog with cutaneous manifestations. Parasites \& Vectors 2016, 9(1):246.

26. Bamorovat M, Sharifi I, Dabiri S, Mohammadi MA, Harandi MF, Mohebali M, Aflatoonian MR, Keyhani A: Leishmania tropica in stray dogs in southeast Iran. Iranian Journal of Public Health 2015, 44(10):1359-1366.

27. Al-Zahrani M, Peters W, Evans D, Chin C, Smith V, Lane R: Phlebotomus sergenti, a vector of Leishmania tropica in Saudi Arabia. Transactions of the Royal Society of Tropical Medicine and Hygiene 1988, 82(3):416.

28. Haouas N, Amer O, Alshammri FF, Al-Shammari S, Remadi L, Ashankyty I: Cutaneous leishmaniasis in northwestern Saudi Arabia: identification of sand fly fauna and parasites. Parasites \& Vectors 2017, 10(1):544. 
29. Peters W, Elbihari S, Liu C, Le Blancq S, Evans D, Killick-Kendrick R, Smith V, Baldwin C: Leishmania infecting man and wild animals in Saudi Arabia 1. General survey. Transactions of the Royal Society of Tropical Medicine and Hygiene 1985, 79(6):831-839.

30. Elbihari S, Kawasmeh Z, Al Naiem A: Possible reservoir host (s) of zoonotic cutaneous leishmaniasis in Al-Hassa oasis, Saudi Arabia. Annals of Tropical Medicine \& Parasitology 1984, 78(5):543-545.

31. Du R, Hotez PJ, Al-Salem WS, Acosta-Serrano A: Old world cutaneous leishmaniasis and refugee crises in the Middle East and North Africa. Public Library of Science; 2016.

32. Mustafa M, Hussein S, Ibrahim E, Al-Seghayer S, Al Amri S, Gradoni L: Phlebotomus papatasi (Scopoli), vector of zoonotic cutaneous leishmaniasis in Riyadh province, Saudi Arabia. Transactions of the Royal Society of Tropical Medicine and Hygiene 1994, 88(1):40.

33. El-Beshbishy HA, Al-Ali KH, El-Badry AA: Molecular characterization of Leishmania infection in sand flies from Al-madinah Al-munawarah province, western Saudi Arabia. Experimental Parasitology 2013, 134(2):211-215.

34. Lima C, Colella V, Latrofa MS, Cardoso L, Otranto D, Alho AM: Molecular detection of Leishmania spp. in dogs and a cat from Doha, Qatar. Parasites \& Vectors 2019, 12(1):125.

35. Mohebali M, Malmasi A, Hajjaran H, Jamshidi S, Akhoundi B, Rezaei M, Janitabar S, Zarei H, Charehdar S: Disseminated leishmaniasis caused by Leishmania tropica in a puppy from Karaj, Central Iran. Iranian Journal of Prasitology 2011, 6(2):69.

36. Baneth G, Zivotofsky D, Nachum-Biala Y, Yasur-Landau D, Botero A-M: Mucocutaneous Leishmania tropica infection in a dog from a human cutaneous leishmaniasis focus. Parasites \& Vectors 2014, 7(1):118.

37. Baneth G, Yasur-Landau D, Gilad M, Nachum-Biala Y: Canine leishmaniosis caused by Leishmania major and Leishmania tropica: comparative findings and serology. Parasites \& Vectors 2017, 10(1):113.

\section{Table}

Table 1: NCBI-BLAST Homology Sequence identity between local L. major and L. tropica isolates and NCBI-Genbank local Leishmania isolate species. 


\begin{tabular}{|c|c|c|c|c|}
\hline \multirow[t]{2}{*}{ Local isolates } & \multicolumn{4}{|c|}{ NCBI-BLAST Homology Sequence identity } \\
\hline & $\begin{array}{l}\text { NCBI BLAST identity } \\
\text { isolate }\end{array}$ & Country & $\begin{array}{c}\text { accession } \\
\text { number }\end{array}$ & $\begin{array}{l}\text { Identity } \\
(100 \%)\end{array}$ \\
\hline $\begin{array}{l}\text { L.tropica Human } \\
\text { No.1 }\end{array}$ & L.tropica & Iran & AB678350.1 & $99.66 \%$ \\
\hline $\begin{array}{l}\text { L.tropica Human } \\
\text { No.3 }\end{array}$ & L.tropica & Iran & AB678350.1 & $99.18 \%$ \\
\hline $\begin{array}{l}\text { L.major Human } \\
\text { No.1 }\end{array}$ & L.major & Iran & LC036307.1 & $99.34 \%$ \\
\hline $\begin{array}{l}\text { L.major Human } \\
\text { No. } 2\end{array}$ & L.major & Iran & LC036307.1 & $99.34 \%$ \\
\hline $\begin{array}{l}\text { L.major Human } \\
\text { No.3 }\end{array}$ & L.major & Iran & LC036307.1 & $99.35 \%$ \\
\hline $\begin{array}{l}\text { L.major Human } \\
\text { No.4 }\end{array}$ & L.major & Iran & LC036307.1 & $99.54 \%$ \\
\hline $\begin{array}{l}\text { L.major Human } \\
\text { No.5 }\end{array}$ & L.major & Iran & LC036307.1 & $99.56 \%$ \\
\hline$\overline{L . t r o p i c a ~ D o g ~ N o .2}$ & L.tropica & Iraq & MF166799. & $99.33 \%$ \\
\hline L.tropica Dog No.4 & L.tropica & Irag & MF166799.1 & $99.33 \%$ \\
\hline L.tropica Dog No.5 & L.tropica & Irag & MF166800.1 & $99.55 \%$ \\
\hline L.tropica Dog No.6 & L.tropica & Iraq & MF166800.1 & $99.55 \%$ \\
\hline L.tropica Dog No.7 & L.tropica & Irag & MF166799.1 & $99.56 \%$ \\
\hline
\end{tabular}

\section{Figures}

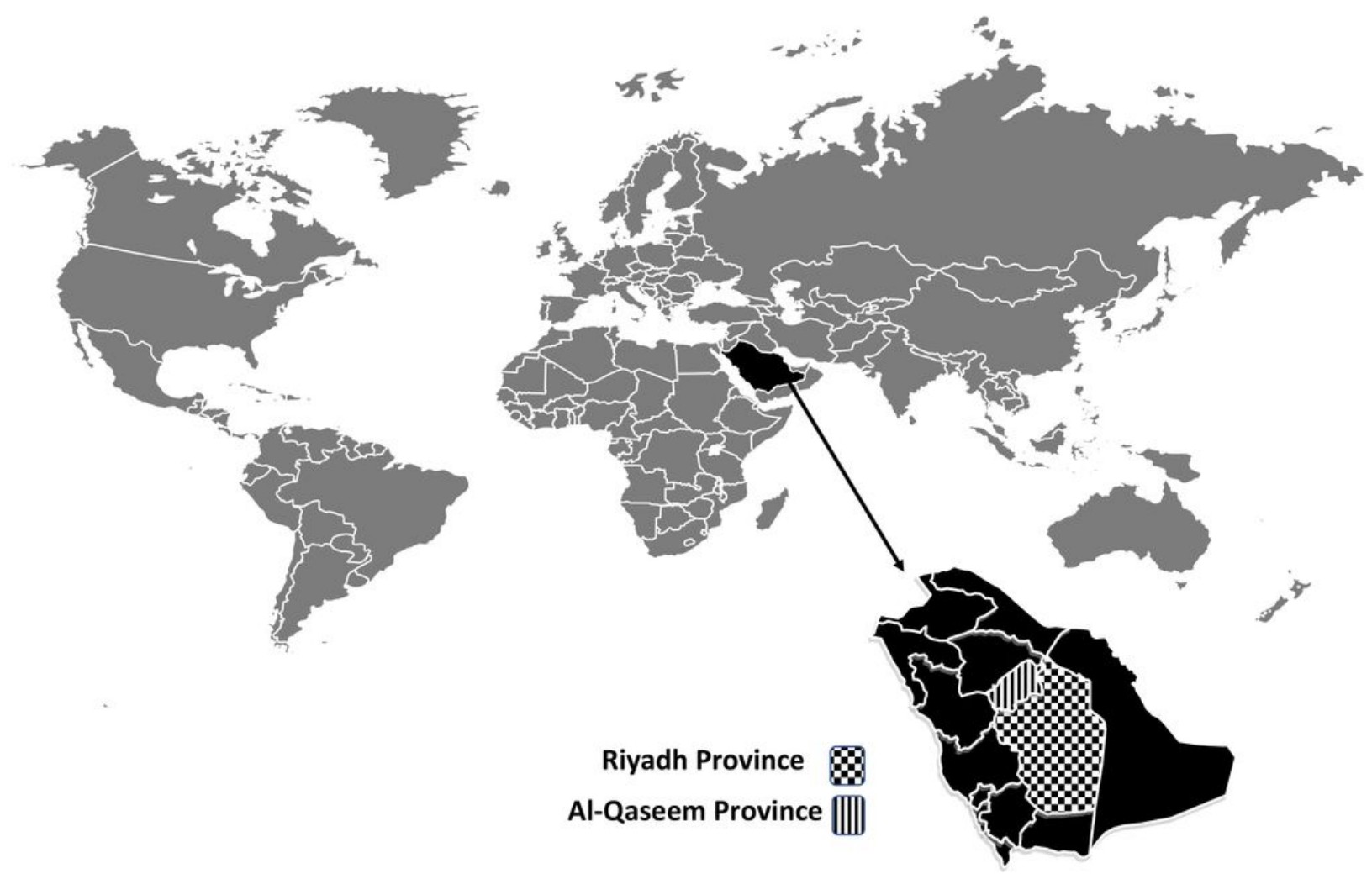

Figure 1 
Map showing the location of the study areas in Saudi Arabia.

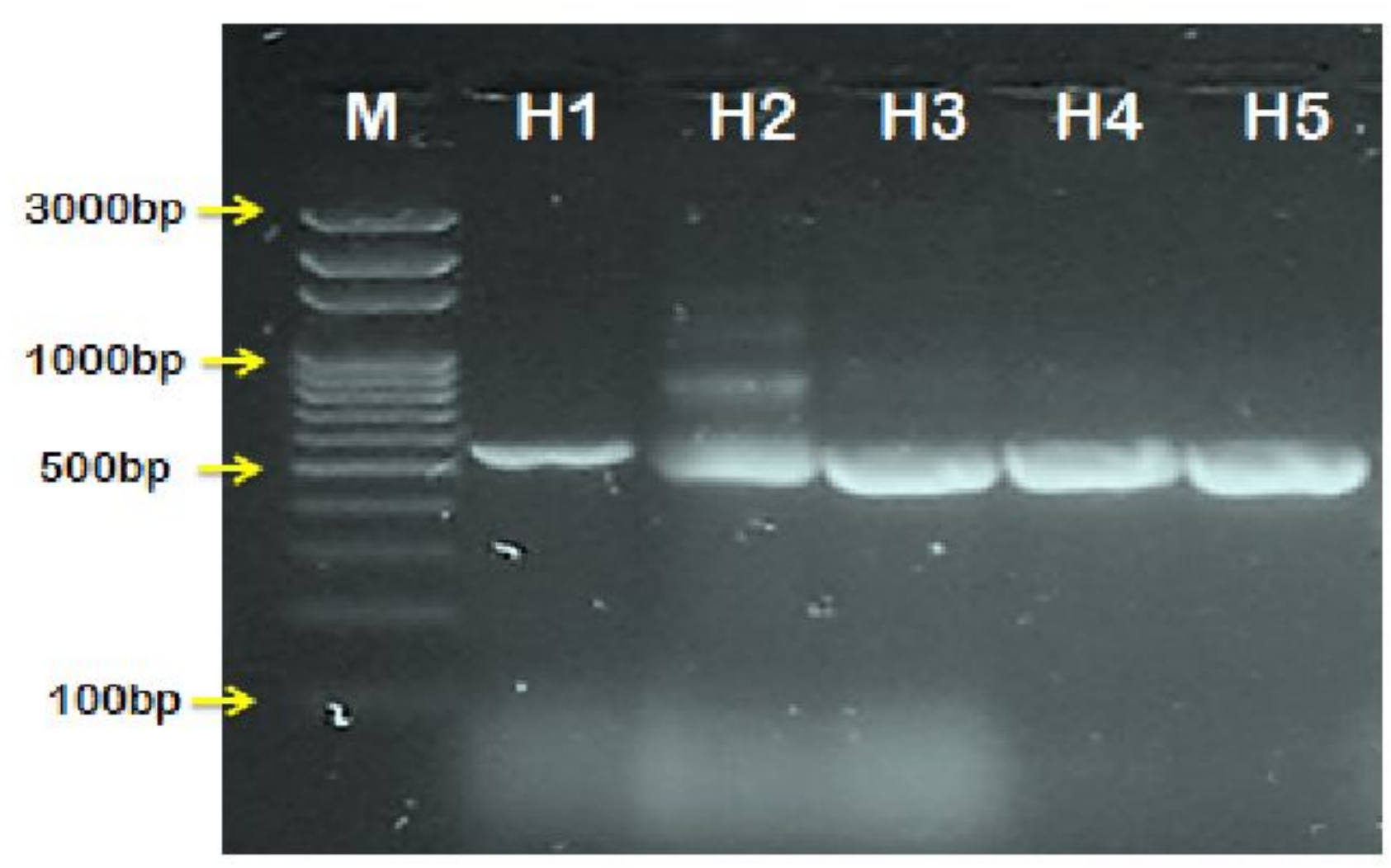

Figure 2

Agarose gel electrophoresis (1.7\%) image that show the Nested PCR product analysis of kDNA in Cutaneous L. major from human skin lesion samples from Riyadh city. Where M: marker (3000-100bp) and lane (H1 - H5) positive Human L. major at (560bp) nPCR product. 


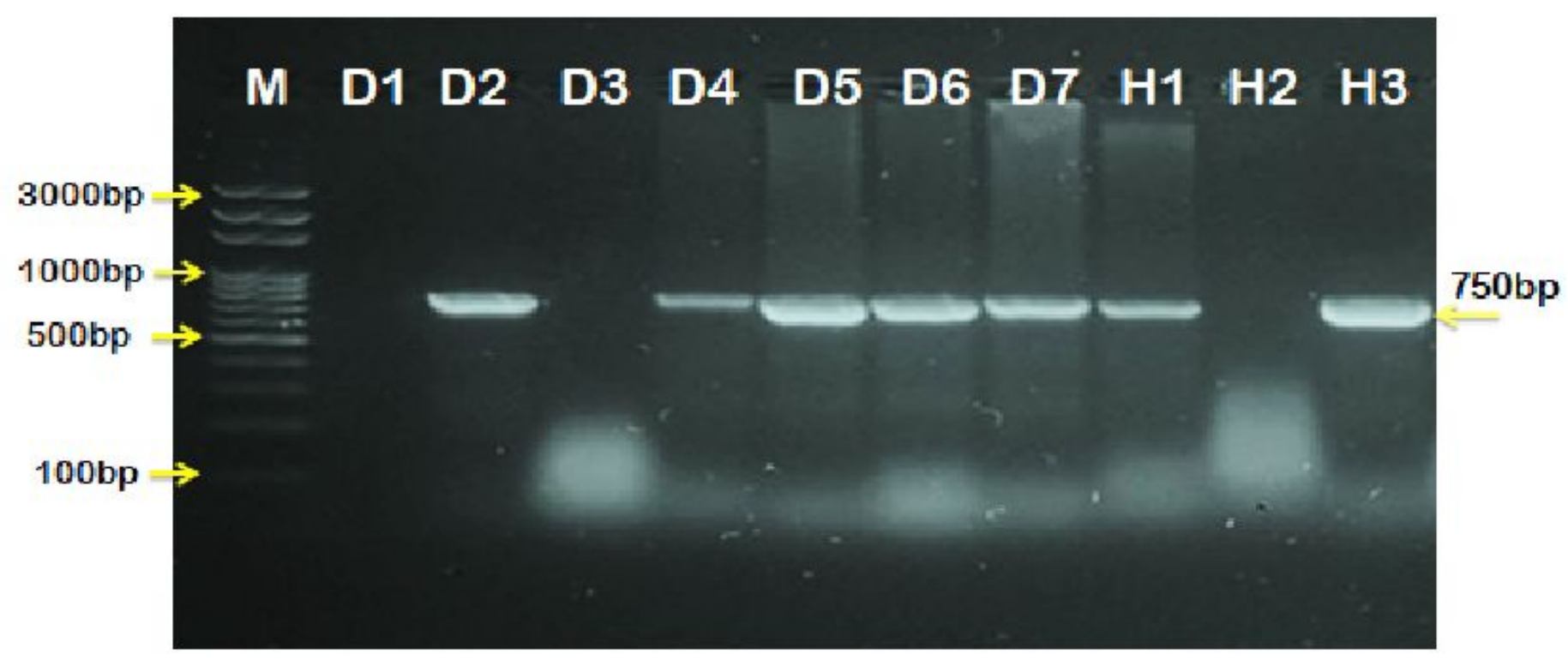

\section{Figure 3}

Agarose gel electrophoresis (1.7\%) image that show the Nested PCR product analysis of kDNA in Cutaneous $\mathrm{L}$. tropica from dogs and human skin lesion samples from Al-Qaseem province. Where $\mathrm{M}$ : marker (3000-100bp), lane (D2 and D4-D7) positive dogs L. tropica and lane (H1 and H3) positive Human L. tropica at $(750 \mathrm{bp}) \mathrm{nPCR}$ product.

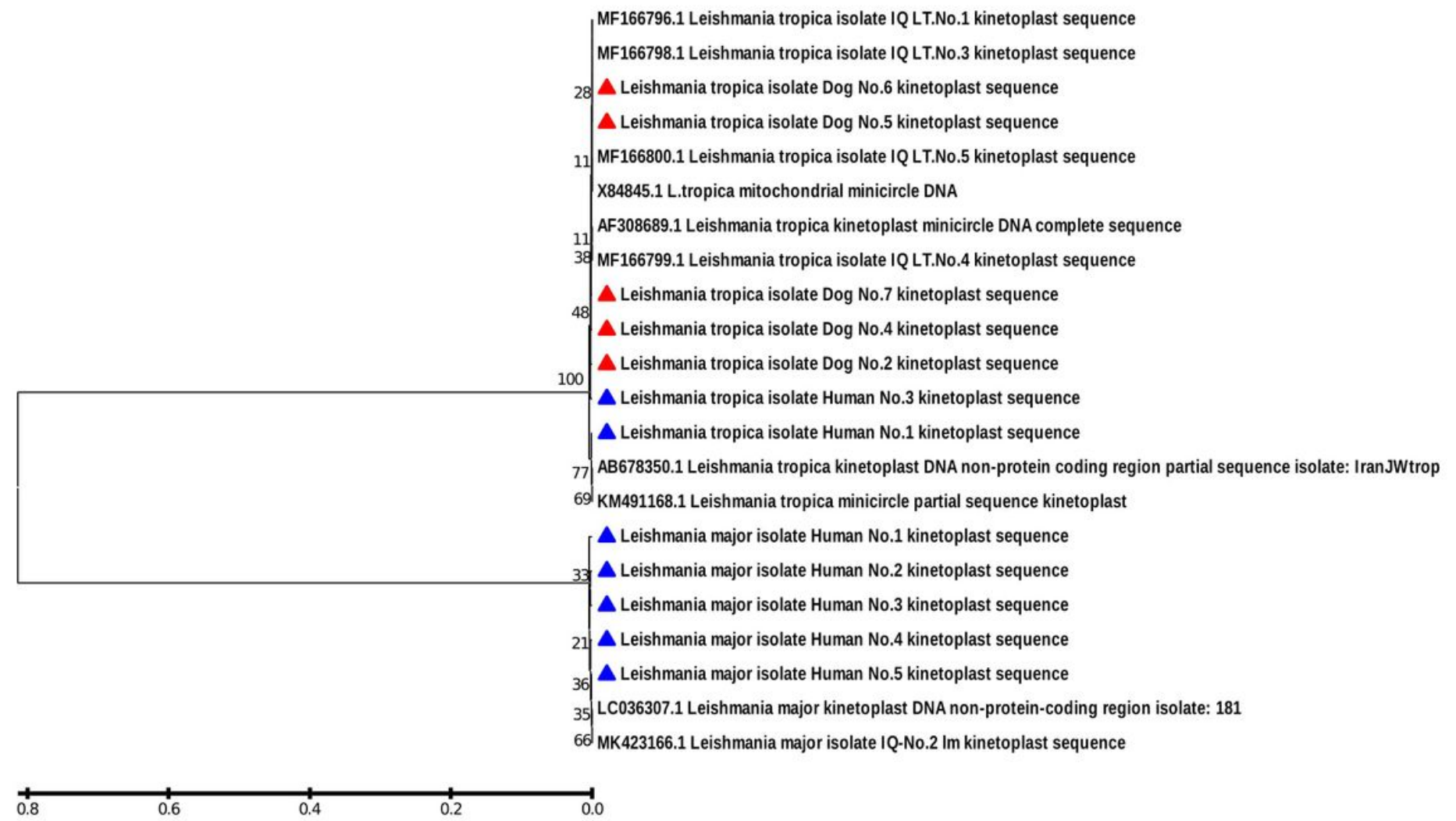




\section{Figure 4}

Phylogenetic tree analysis based on the partial sequence of kinetoplast DNA, non-protein coding region in local L.major and L. tropica human and dogs isolates that used for confirmative genetic detection and genetic relationship analysis. The evolutionary distances were computed using phylogenetic UPGMA tree type (MEGA 7.0 version). 